\title{
Stress, altered energy availability and larval fitness in Drosophila melanogaster
}

\author{
Michael J. Kohane
}

\author{
Department of Genetics and Human Variation, \\ La Trobe University, Bundoora, \\ Victoria 3083, Australia.
}

This paper reports some effects of temperature variation, nutritional stress and a novel alteration in energy availability upon larval fitness in Drosophila melanogaster. The cofactor nicotinamide adenine dinucleotide (NAD) has been chosen as a novel energy source to be supplemented in food during larval development. The effects have been assessed at the phenotypic level for larval survival and development time and at the genotypic level for the alcohol dehydrogenase (Adh) and glycerol-3-phosphate dehydrogenase (Gpdh) loci. Supplemented NAD was found to increase survival at the lower temperatures and decrease survival at the higher temperatures. Further, for each temperature, NAD decreased development time although this effect diminished as temperature increased. There were no significant effects at the genotypic level. Hence a phenotypic approach studying the effects of environmental stresses and novel energy availability may be useful in understanding fitness variation in Drosophila populations.

\section{INTRODUCTION}

Kohane and Parsons (1986) emphasised the need to commence at the phenotypic level to understand fitness relations in natural populations. In a study of temperature-dependent fitness differences and the alcohol dehydrogenase locus (Adh) in Drosophila melanogaster, these authors suggested that direct assessments of environmental stresses of ecological importance may provide an initial strategy. This paper adopts these ideas and additionally follows Watt's $(1985,1986)$ proposal that a bioenergetic approach can be helpful in evolutionary genetics. This is by studying energy flow through organisms leading to a unification of biochemical and ecological aspects. Results are presented here on the effects of environmental stress, together with a novel alteration in energy availability, upon larval fitness in $D$. melanogaster. The larval fitnesses of genotypes at the Adh and glycerol-3-phosphate dehydrogenase (Gpdh) loci have been estimated to investigate possible single locus selection.

Temperature variation (Kohane and Parsons, 1986) and food of limited nutrient value (Bakker, 1961) are the environmental stresses and the cofactor nicotinamide adenine dinucleotide (NAD) is the novel energy source to be supplemented in food during larval development. NAD is chosen on the basis of its direct participation in the electron transport chain, oxidative phosphorylation and thus ATP production (fig. 1; Jeffrey, 1980; Geer et al., 1983); and its associated role as a cofactor for many dehydrogenases, including ADH and GPDH (Conway and Koshland, 1968; Page, 1976; Branden and Eklund, 1980). NAD is thus considered a molecule of broad metabolic and physiological function (Lehninger, 1971, 1982) and contrasts with the specific molecules such as substrates, intermediates or end-products of particular metabolic pathways commonly used in the assessment of the adaptive significance of allozyme polymorphisms (Clarke, 1975).

The hypothesis to be considered here is that the presence of a novel energy source, NAD, together with temperature variation (i.e., a temperature $\times$ NAD interaction), can modify metabolic and physiological processes during larval development, leading to changes in the larval phenotype. This modification, together with stressful nutrient conditions, may in turn enhance differences in the functional abilities of the ADH and GPDH allozymes during critical developmental periods when their respective structural and regulatory genes are expressed.

The experiments presented therefore assess larval survival and development time under the stressful nutrient conditions of limited yeast and no 

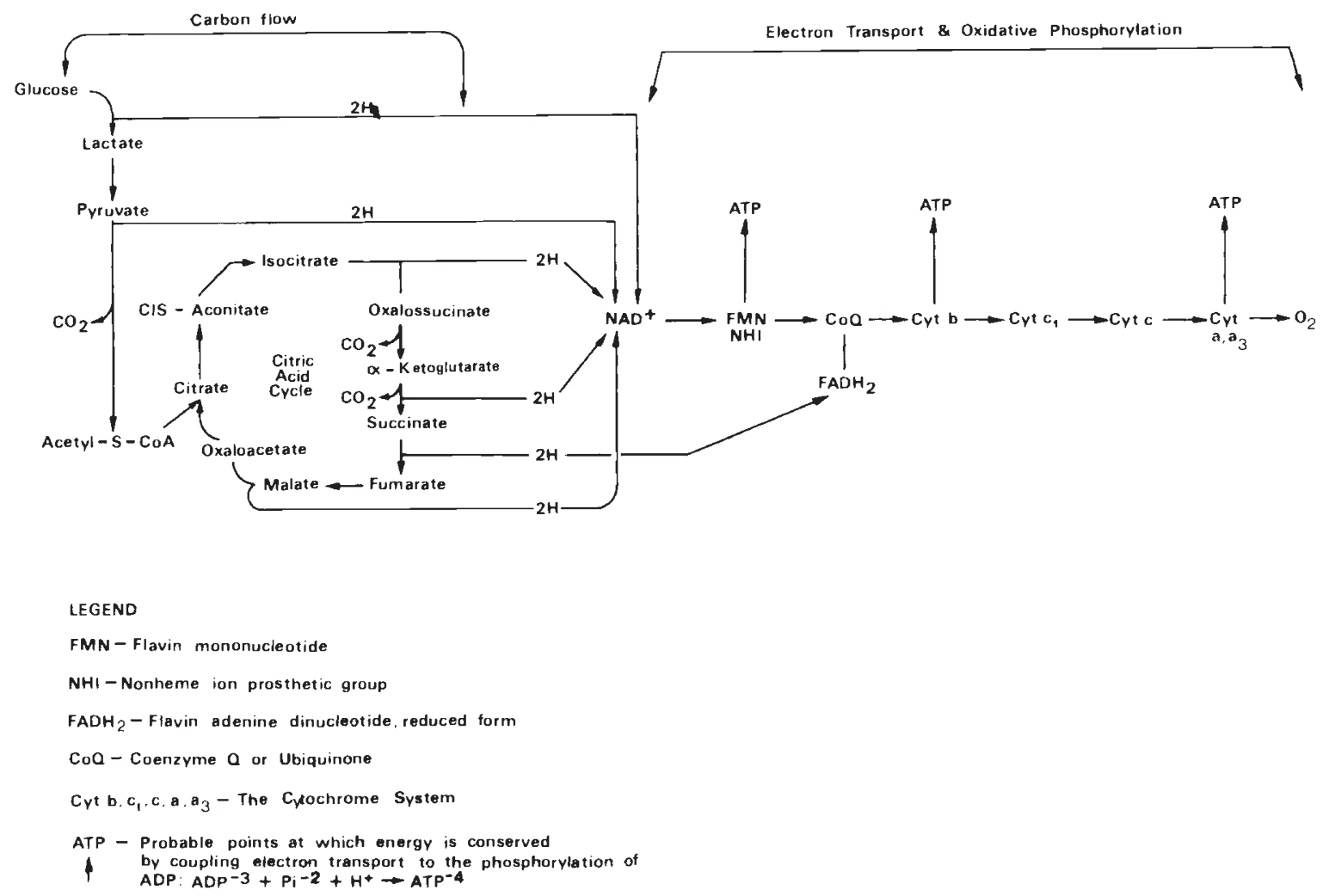

Figure 1 Diagram of pathways of carbon flow (left-hand side) and electron flow (right-hand side) in metabolism. The principal direction of flow is indicated by the arrows. Diagram modified from J. Larner, Intermediary Metabolism and its Regulation, Prentice-Hall, 1971; and D. S. Page, Principles of Biological Chemistry, Willard Grant Press, 1976.

glucose, in the presence and absence of NAD, at $15^{\circ} \mathrm{C}, 20^{\circ} \mathrm{C}, 25^{\circ} \mathrm{C}$ and $29^{\circ} \mathrm{C}$. The survival and development times of the common Adh and Gpdh genotypes have been determined at $15^{\circ} \mathrm{C}, 25^{\circ} \mathrm{C}$ and $29^{\circ} \mathrm{C}$.

\section{MATERIALS AND METHODS}

\section{Derivation of the larvae}

Approximately $1000 \mathrm{D}$. melanogaster adults were collected at the Chateau Tahbilk winery (Seymour, Victoria) by sweeping with a net over a pile of grape refuse during March 1981. These flies were randomly assigned to 3 lots of approximately 330 flies and transferred to empty half-pint milk bottles. Food-covered watch-glasses were taped to the mouths of the bottles which were inverted and cultured at $25^{\circ} \mathrm{C}$ for 6 hours, after which time the adults were discarded. Larvae were collected from the watch-glasses following a further 18 hours culture at $25^{\circ} \mathrm{C}$.

\section{Food composition and preparation}

The basic food in these experiments contained limited amounts of yeast and no glucose. The yeast concentration of $1.27 \mathrm{mg} /$ larvae was selected as one which significantly restricted nutrient levels (McKechnie et al., 1981). Only larvae which develop relatively rapidly in these stressful conditions reach their critical weight for pupation before resources are exhausted (Bakker, 1961).

Each test vial contained a base agar layer $(3 \cdot 0$ per cent agar, 1.0 per cent nipagen) of $5.0 \mathrm{ml}$. This was prepared first and left to set for 24 hours. The $2.0 \mathrm{ml}$ food layer then added contained 1.0 per cent agar, $1.27 \mathrm{mg} /$ larvae yeast, 1.0 per cent nipagen and either 0.0 or $0.5 \mathrm{mg} /$ larvae NAD. The NAD was added after the other ingredients had been cooked and cooled to a point just prior to setting. Sixty larvae ( 0 to 3 hours old) were transferred to each vial within 2 hours of preparation and the vials were randomly assigned to 4 temperatures: $15^{\circ} \mathrm{C}, 20^{\circ} \mathrm{C}, 25^{\circ} \mathrm{C}$ and $29^{\circ} \mathrm{C}$. There were 5 replicates for each NAD level at each tem- 
perature. NAD was obtained from Boehringer. Additionally, 25 larvae were transferred to vials containing $16.5 \mathrm{ml}$ of standard food and cultured at $25^{\circ} \mathrm{C}$. There were 7 replicates in this case and these were denoted controls. The vials werè monitored daily and when emergence began, adults were collected twice daily (a.m. and p.m.). The Adh and Gpdh genotypes were determined for each surviving fly at all temperatures except $20^{\circ} \mathrm{C}$. Electrophoretic details were similar to those in Ayala et al. (1972). It is assumed that the supplemented NAD is ingested and utilised by the developing larvae (Fiegelson et al., 1951; Chaykin, 1967; Schwartz et al., 1975).

\section{RESULTS}

Figure 2 gives the mean number of flies surviving at each temperature and NAD level and table 1 gives the corresponding ANOVA. It is clear that

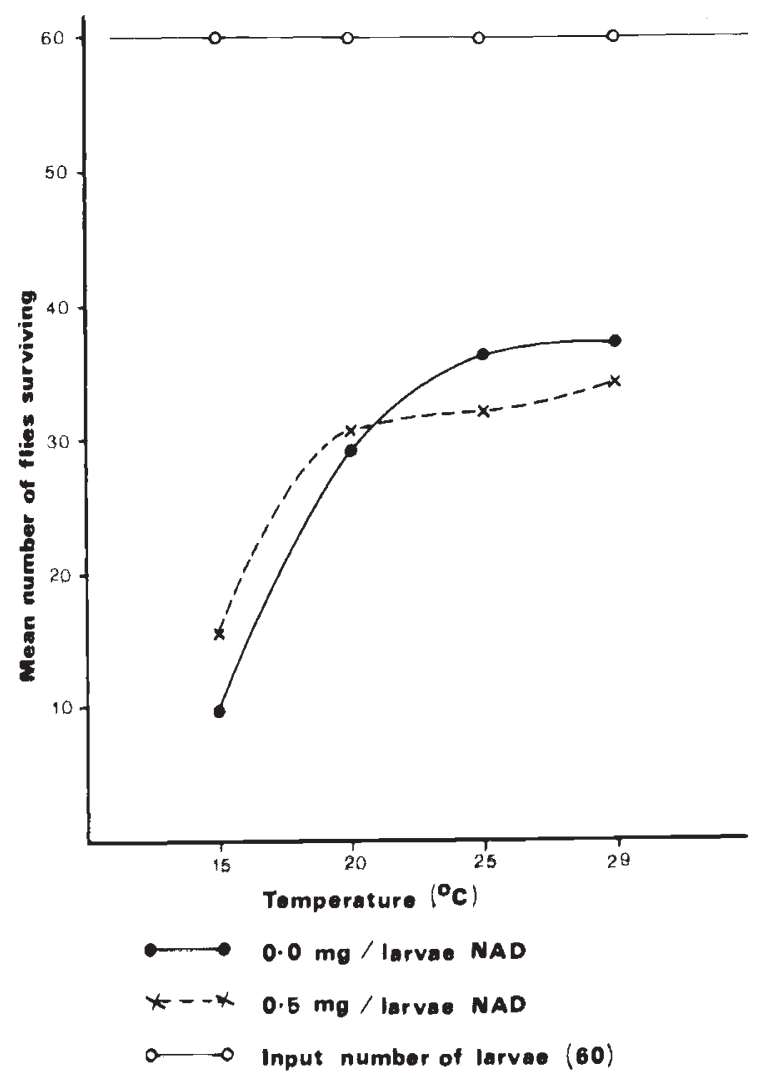

Figure 2 The mean number of flies surviving in five replicates at each temperature $\left(15^{\circ} \mathrm{C}, 20^{\circ} \mathrm{C}, 25^{\circ} \mathrm{C}\right.$ and $\left.29^{\circ} \mathrm{C}\right)$ and NAD level $(0.0$ and $0.5 \mathrm{mg} /$ larvae). Sixty larvae, derived from flies collected at Chateau Tahbilk, were initially transferred to a single vial. all nutrient conditions significantly restricted larval survival because all survival values were well below the input of 60 larvae. Temperature and the temperature $\times$ NAD interaction exerted significant effects on survival but NAD did not. The effect of temperature was such that survival increased from a minimum at $15^{\circ} \mathrm{C}$ to a maximum at $29^{\circ} \mathrm{C}$. The significant temperature $\times \mathrm{NAD}$ interaction was evident in fig. 2 where the shapes of the survival curves for both NAD levels differ. In the absence of NAD there was a smooth increase in the number of flies surviving from $15^{\circ} \mathrm{C}$ to $29^{\circ} \mathrm{C}$. However, in the presence of NAD relatively more flies survived at $15^{\circ} \mathrm{C}$ and $20^{\circ} \mathrm{C}$ and relatively fewer flies survived at $25^{\circ} \mathrm{C}$ and $29^{\circ} \mathrm{C}$.

Figure 3 gives the mean development times of the surviving flies at each temperature and NAD level and the corresponding ANOVA is table 2. Development time is expressed as $T_{1 / 2}$, the time taken for half of the surviving flies to emerge, and is given in days. Temperature, NAD level and the interaction effect were significant in the ANOVA. Development time decreased as temperature increased, and the presence of NAD significantly decreased development time compared with

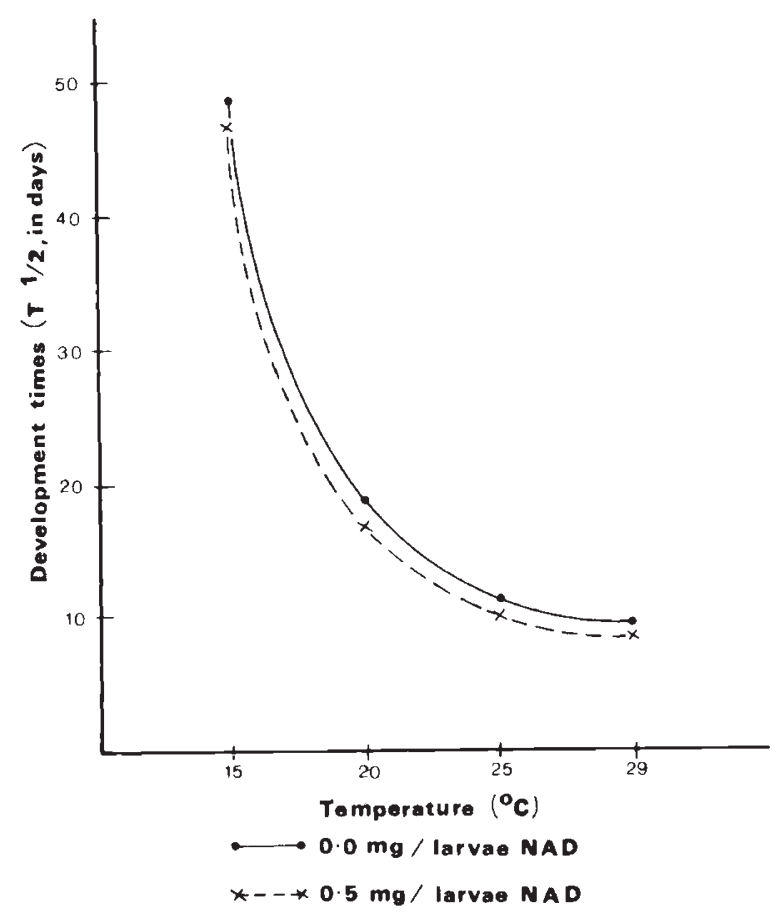

Figure 3 The mean development times ( $T_{1 / 2}$, in days) of surviving flies in five replicates at each temperature $\left(15^{\circ} \mathrm{C}\right.$, $20^{\circ} \mathrm{C}, 25^{\circ} \mathrm{C}$ and $\left.29^{\circ} \mathrm{C}\right)$ and NAD level $(0.0$ and $0.5 \mathrm{mg} / \mathrm{lar}-$ vae). The larvae used in this experiment were immediately derived from flies collected at Chateau Tahbilk. 
Table 1 ANOVA for the number of flies surviving in five replicates at each temperature $\left(15^{\circ} \mathrm{C}, 20^{\circ} \mathrm{C}, 25^{\circ} \mathrm{C}\right.$ and $\left.29^{\circ} \mathrm{C}\right)$ and NAD level $(0.0$ and $0.5 \mathrm{mg} /$ larvae $)$. The larvae used in this experiment were immediately derived from flies collected at Chateau Tahbilk

\begin{tabular}{|c|c|c|c|c|}
\hline Variable & $\mathrm{df}$ & ss & $\mathrm{ms}$ & $F$ \\
\hline Temperature $(T)$ & 3 & $229 \cdot 9$ & $76 \cdot 6$ & $66 \cdot 1^{* *}$ \\
\hline NAD level $(L)$ & 1 & $0 \cdot 2$ & $0 \cdot 2$ & $0 \cdot 2$ \\
\hline$T \times L$ & 3 & $14 \cdot 8$ & 4.9 & $4 \cdot 3^{*}$ \\
\hline Residual & 32 & $37 \cdot 2$ & $1 \cdot 2$ & \\
\hline
\end{tabular}

** $P<0.005$.

$* P<0.05$.

Table 2 ANOVA for the development times of surviving flies in five replicates at each temperature $\left(15^{\circ} \mathrm{C}, 20^{\circ} \mathrm{C}, 25^{\circ} \mathrm{C}\right.$ and $\left.29^{\circ} \mathrm{C}\right)$ and NAD level $(0.0$ and $0.5 \mathrm{mg} /$ larvae $)$. Development time has been expressed as $T_{1 / 2}$, the time taken for half of the surviving flies to emerge. The larvae used in this experiment were immediately derived from flies collected at Chateau Tahbilk

\begin{tabular}{|c|c|c|c|c|}
\hline Variable & $\mathrm{df}$ & ss & $\mathrm{ms}$ & $\mathbf{F}$ \\
\hline Temperature $(T)$ & 3 & $9,358 \cdot 0$ & $3,119 \cdot 3$ & $16,417 \cdot 5^{* *}$ \\
\hline NAD level $(L)$ & 1 & $20 \cdot 0$ & $20 \cdot 0$ & $105 \cdot 3^{* *}$ \\
\hline$T \times L$ & 3 & $5 \cdot 4$ & 1.8 & $9 \cdot 4^{*}$ \\
\hline Residual & 32 & $6 \cdot 2$ & & \\
\hline
\end{tabular}

** $P<0.005$.

$* P<0.01$.

development time in its absence. Considering the interaction, the differences in development times in the presence and absence of NAD were greatest at the lowest temperature, $15^{\circ} \mathrm{C}$, and decreased as temperature increased to $29^{\circ} \mathrm{C}$.

As noted in the Materials and Methods, allozyme genotypes were determined for flies surviving at $15^{\circ} \mathrm{C}, 25^{\circ} \mathrm{C}$ and $29^{\circ} \mathrm{C}$ but not $20^{\circ} \mathrm{C}$. The survival of each genotype was estimated indirectly by comparing the number of genotypes surviving in the control conditions with the number surviving at each temperature and NAD level. This was necessary since the initial genotypic distributions were not known in this experiment. As previously noted, survival in the stressful nutrient conditions was only approximately 50 per cent but in the control it was approximately 80 per cent; therefore such comparisons should detect genotypic differences (Kohane and Parsons, 1986).

Table $3 \mathrm{~A}$ gives the number of individuals of each Adh genotype surviving (pooled values) in the controls and at each temperature and NAD level. $\chi_{2}^{2}$ values for the above comparisons are also shown. No value was significant indicating no significant genotypic effects on survival. This result was confirmed by comparisons between genotypic survival for $0.0 \mathrm{mg} /$ larvae NAD and $0.5 \mathrm{mg} /$ larvae $\mathrm{NAD}$ at each temperature where there were no significant $\chi_{2}^{2}$ values $\left(15^{\circ} \mathrm{C}: \chi_{2}^{2}=1 \cdot 72 ; 25^{\circ} \mathrm{C}: \chi_{2}^{2}=\right.$ $\left.2 \cdot 50 ; 29^{\circ} \mathrm{C}: \chi_{2}^{2}=2.01 ; P>0.05\right)$.

Table $3 \mathrm{~B}$ gives the number of flies of each $\mathrm{Gpdh}$ genotype surviving (pooled values) in the controls and at each temperature and NAD level. There was a single significant $\chi_{2}^{2}$ value at $15^{\circ} \mathrm{C}$ for $0.0 \mathrm{mg} /$ larvae NAD $(P<0.05)$ and this appeared to be due to the low expected value for GpdhSS and the few survivors in this circumstance. It therefore appeared that there were no significant genotypic effects on survival. This result was confirmed by comparisons between genotypic survival for $0.0 \mathrm{mg} /$ larvae $\mathrm{NAD}$ and $0.5 \mathrm{mg} /$ larvae $\mathrm{NAD}$ at each temperature where there were no significant $\chi_{2}^{2}$ values $\left(15^{\circ} \mathrm{C}: \chi_{2}^{2}=5 \cdot 55 ; 25^{\circ} \mathrm{C}: \chi_{2}^{2}=\right.$ $\left.4.54 ; 29^{\circ} \mathrm{C}: \chi_{2}^{2}=2.58 ; P>0.05\right)$.

Table 4 gives the number of Adh-Gpdh genotypes surviving (pooled values) in the controls and at each temperature and NAD level. No $\chi_{8}^{2}$ value was significant indicating no significant genotypic effects on survival. A test of independence using all the data was also not significant $\left(\chi_{42}^{2}=47 \cdot 7\right)$. This result was confirmed by comparisons between genotypic survival for $0.0 \mathrm{mg} /$ larvae NAD and $0.5 \mathrm{mg} /$ larvae NAD at each temperature where there were no significant $\chi_{8}^{2}$ values $\left(15^{\circ} \mathrm{C}: \chi_{8}^{2}=13.64 ; 25^{\circ} \mathrm{C}: \chi_{8}^{2}=10 \cdot 46\right.$; $\left.29^{\circ} \mathrm{C}: \chi_{8}^{2}=5.77 ; P>0.05\right)$. The possibility of a fitness interaction between Adh and Gpdh genotypes in response to temperature variation, nutrient stress and the presence of NAD has also been preliminarily assessed for these data. All contingency table tests of independence (pooled values) were not significant (control, $\chi_{4}^{2}=3 \cdot 72$; $15^{\circ} \mathrm{C}, 0.0 \mathrm{mg} /$ larvae NAD $\chi_{4}^{2}=5 \cdot 59,0.5 \mathrm{mg} /$ larvae NAD $\chi_{4}^{2}=5 \cdot 20 ; 25^{\circ} \mathrm{C}, 0.0 \mathrm{mg} /$ larvae NAD $\chi_{4}^{2}=$ $4.66, \quad 0.5 \mathrm{mg} /$ larvae $\mathrm{NAD} \quad \chi_{4}^{2}=5.48 ; \quad 29^{\circ} \mathrm{C}$, $0.0 \mathrm{mg} /$ larvae NAD $\chi_{4}^{2}=6.13, \quad 0.5 \mathrm{mg} /$ larvae NAD $\chi_{4}^{2}=3 \cdot 52$ ).

The larval to adult development times of the Adh and Gpdh genotypes at each temperature and NAD level are shown in table 5. The development times of the Adh-Gpdh genotypes have not been given since the survivorship of some genotypes was too low to determine reliable $T_{1 / 2}$ estimates (table 4). The ANOVA is only given for the Adh locus because there were too few survivors at $15^{\circ} \mathrm{C}$ for 0.0 and $0.5 \mathrm{mg} /$ larvae NAD respectively to obtain an estimate of the development time of GpdhSS. Considering the ANOVA for Adh, significant factors were temperature, NAD and the temperature $\times$ NAD interaction. Genotype was not 
Table 3 The number of Adh and Gpdh genotypes (pooled values) surviving in control culture conditions $\left(25^{\circ} \mathrm{C}\right)$ and at each temperature $\left(15^{\circ} \mathrm{C}, 25^{\circ} \mathrm{C}, 29^{\circ} \mathrm{C}\right)$ and NAD level $(0.0$ and $0.5 \mathrm{mg} /$ larvae) $\chi_{2}^{2}$ tests, representing comparisons between the values for the control culture conditions and each experimental culture condition, are also given

(A) Adh

\begin{tabular}{lllllll} 
& \multicolumn{5}{c}{ Adh genotype } \\
\cline { 5 - 7 } Temp. $\left({ }^{\circ} \mathrm{C}\right)$ & $\begin{array}{l}\text { NAD level } \\
(\mathrm{mg} / \text { larvae })\end{array}$ & FF & FS & SS & Total & $\chi_{2}^{2}$ \\
\hline Control $\left(25^{\circ} \mathrm{C}\right)$ & & 36 & 66 & 37 & 139 & \\
15 & 0.0 & 13 & 23 & 13 & 49 & 0.01 \\
& 0.5 & 29 & 38 & 15 & 82 & 4.99 \\
25 & 0.0 & 49 & 81 & 51 & 181 & 0.56 \\
& 0.5 & 51 & 77 & 34 & 162 & 3.87 \\
29 & 0.0 & 48 & 84 & 53 & 185 & 0.47 \\
& 0.5 & 49 & 85 & 38 & 172 & 1.88 \\
\hline
\end{tabular}

(B) Gpdh

\begin{tabular}{llrrrrr} 
& \multicolumn{6}{c}{ Gpdh genotype } \\
Temp. $\left({ }^{\circ} \mathrm{C}\right)$ & $\begin{array}{l}\text { NAD level } \\
(\mathrm{mg} / \text { larvae })\end{array}$ & FF & FS & SS & Total & \multirow{2}{*}{$\chi_{2}^{2}$} \\
\hline Control $\left(25^{\circ} \mathrm{C}\right)$ & & 82 & 47 & 10 & 139 & \\
15 & 0.0 & 27 & 14 & 8 & 49 & $6 \cdot 19^{*}$ \\
25 & 0.5 & 45 & 33 & 4 & 82 & $1 \cdot 86$ \\
& 0.0 & 109 & 53 & 19 & 181 & $3 \cdot 88$ \\
29 & 0.5 & 84 & 65 & 13 & 162 & 3.46 \\
& 0.0 & 105 & 62 & 18 & 185 & 1.80 \\
& 0.5 & 103 & 60 & 9 & 172 & 1.00 \\
\hline
\end{tabular}

$* P<0.05$.

Table 4 The numbers of $\mathrm{Adh}-\mathrm{Gpdh}$ genotypes (pooled values) surviving in the control culture conditions $\left(25^{\circ} \mathrm{C}\right.$ ) and at each temperature $\left(15^{\circ} \mathrm{C}, 25^{\circ} \mathrm{C}\right.$ and $\left.29^{\circ} \mathrm{C}\right)$ and NAD level $(0.0$ and $0.5 \mathrm{mg} /$ larvae $) . \chi_{2}^{2}$ tests, representing comparisons between the values for the control culture conditions and each experimental culture condition, are also given. The genotypes are displayed left to right as follows: Gpdh ${ }^{\mathrm{FF}}\left(\mathrm{Adh}^{\mathrm{FF}}, \mathrm{Adh}^{\mathrm{FS}}, \mathrm{Adh}^{\mathrm{SS}}\right) ; \mathrm{Gpdh}^{\mathrm{FS}}\left(\mathrm{Adh}^{\mathrm{FF}}, \mathrm{Adh}^{\mathrm{FS}}, \mathrm{Adh}^{\mathrm{SS}}\right) ; \mathrm{Gpdh}^{\mathrm{SS}}\left(\mathrm{Adh}{ }^{\mathrm{FF}}, \mathrm{Adh}^{\mathrm{FS}}, \mathrm{Adh}^{\mathrm{SS}}\right)$

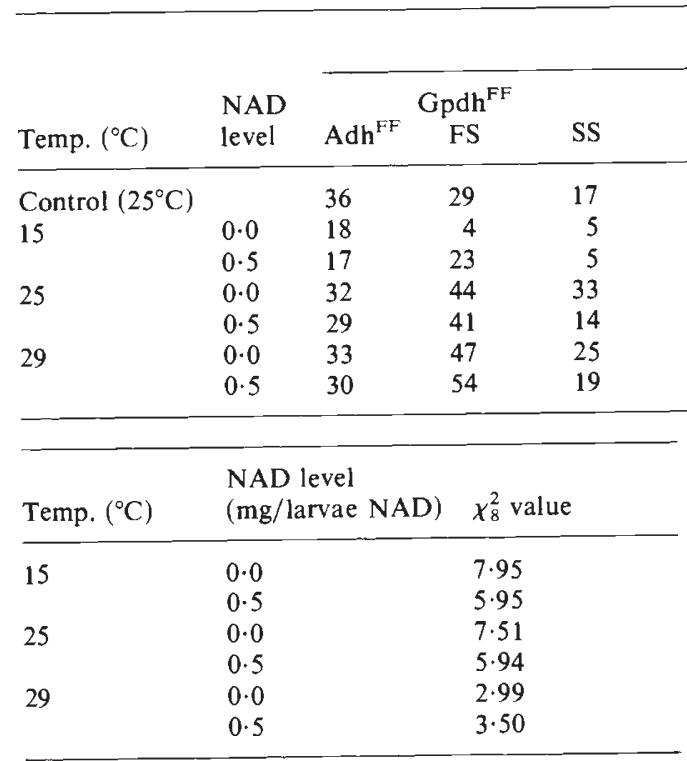

\section{Genotypes}


Table 5 Larval to adult development time

(A) The mean larval to adult development times $\left(T_{1 / 2}\right.$, in days) of Adh and $\mathrm{Gpdh}$ genotypes surviving at each temperature (15 ${ }^{\circ} \mathrm{C}$, $25^{\circ} \mathrm{C}$ and $\left.29^{\circ} \mathrm{C}\right)$ and NAD level $(0.0$ and $0.5 \mathrm{mg} /$ larvae $)$. Standard errors are also shown

\begin{tabular}{|c|c|c|c|c|c|c|c|}
\hline \multirow[b]{2}{*}{$\begin{array}{l}\text { Temp. } \\
\left({ }^{\circ} \mathrm{C}\right)\end{array}$} & \multirow[b]{2}{*}{$\begin{array}{l}\text { NAD level } \\
\text { (mg/larvae) }\end{array}$} & \multicolumn{6}{|c|}{ Genotypes } \\
\hline & & $\mathrm{FF}$ & $\begin{array}{l}\text { Adh } \\
\text { FS }\end{array}$ & SS & $\mathrm{FF}$ & $\begin{array}{l}\text { Gpdh } \\
\text { FS }\end{array}$ & SS \\
\hline \multirow[t]{2}{*}{15} & $0 \cdot 0$ & $48 \cdot 17 \pm 0 \cdot 43$ & $48 \cdot 40 \pm 0.64$ & $48 \cdot 21 \pm 0 \cdot 55$ & $48.43 \pm 0.63$ & $47 \cdot 70 \pm 1 \cdot 44$ & $*$ \\
\hline & 0.5 & $45 \cdot 53 \pm 1 \cdot 05$ & $45 \cdot 80 \pm 0 \cdot 86$ & $46 \cdot 63 \pm 1 \cdot 35$ & $45.47 \pm 0.93$ & $45 \cdot 60 \pm 0.91$ & $*$ \\
\hline 25 & 0.0 & $11 \cdot 72 \pm 0 \cdot 51$ & $11 \cdot 30 \pm 0 \cdot 22$ & $11.42 \pm 0.17$ & $11 \cdot 35 \pm 0.05$ & $11.45 \pm 0.17$ & $11.52 \pm 0.61$ \\
\hline 29 & 0.5 & $8 \cdot 79 \pm 0 \cdot 12$ & $8 \cdot 82 \pm 0.06$ & $8.78 \pm 0.07$ & $8.84 \pm 0.06$ & $8 \cdot 71 \pm 0.17$ & $8.75 \pm 0.02$ \\
\hline
\end{tabular}

(B) ANOVA for the development times of the Adh genotypes surviving at each temperature $\left(15^{\circ} \mathrm{C}, 25^{\circ} \mathrm{C}\right.$ and $\left.29^{\circ} \mathrm{C}\right)$ and $\mathrm{NAD}$ level $\left(0.0\right.$ and $0.5 \mathrm{mg} /$ larvae). The ANOVA for the $\mathrm{Gpdh}$ locus has not been given because there were too few survivors at $15^{\circ} \mathrm{C}$ for 0.0 and $0.5 \mathrm{mg} /$ larvae NAD to obtain an estimate of the development time of $\mathrm{Gpdh}^{\mathrm{SS}}$

\begin{tabular}{lrrrr}
\hline Variable & df & SS & MS & F \\
\hline Temperature $(T)$ & 2 & $24,799 \cdot 2$ & $12,399 \cdot 6$ & $34,530 \cdot 0^{* *}$ \\
NAD level $(L)$ & 1 & $41 \cdot 4$ & $41 \cdot 4$ & $115 \cdot 3^{* *}$ \\
Genotype $(G)$ & 2 & $0 \cdot 6$ & $0 \cdot 3$ & $0 \cdot 8$ \\
$T \times L$ & 2 & $10 \cdot 8$ & $5 \cdot 4$ & $15 \cdot 1^{* *}$ \\
$T \times G$ & 4 & $1 \cdot 6$ & $0 \cdot 4$ & $1 \cdot 1$ \\
$L \times G$ & 2 & $0 \cdot 4$ & $0 \cdot 2$ & $0 \cdot 5$ \\
$T \times L \times G$ & 4 & $1 \cdot 9$ & $0 \cdot 5$ & $1 \cdot 3$ \\
Residual & 68 & $24 \cdot 2$ & $0 \cdot 4$ & \\
\hline
\end{tabular}

* Indicates that development time values could not be calculated because of insufficient surviving adults.

** $P<0.001$.

significant. This analysis therefore accords with that for development time independent of Adh genotype (table 2). Comparisons between the mean development times of the Gpdh genotypes also indicated that there were no significant differences in development times between genotypes.

\section{DISCUSSION}

The data presented here indicate that a temperature $\times$ NAD interaction can modify aspects of the larval phenotype-at the lower temperatures tested NAD enhanced survival while at the higher temperatures NAD reduced survival. Further, for each temperature, the presence of NAD decreased development time, although this effect diminished as temperature increased.

It is important to attempt to explain the likely novel functional activity detected here for supplemented NAD during larval development. Firstly, supplemented NAD could have acted as an additional energy source under the limited nutrient conditions. Therefore, sucrose and glucose may have had a similar effect and this possibility is currently being assessed. Secondly, supplemented NAD could have acted as a substrate for a variety of dehydrogenases, enhancing metabolic activity as a consequence of improved substrate availability under the limited nutrient conditions. Dehydrogenases requiring NAD are slow reacting enzymes with NAD dissociation being the rate-limiting step (Jeffrey, 1980). Therefore, increasing the cytosol NAD concentration under stress could enable these enzymes to reach optimum activity levels and positively affect the cytosol NAD/NADH ratio as described for rabbit muscle glycerol-3-phosphate dehydrogenase by Conway and Koshland (1968). Dietary stress can disrupt an organism's NAD/NADH ratio, which under normal metabolic conditions is strictly regulated, leading to many metabolic abnormalities (Veech, 1974; Veech et al., 1972; McElfresh and McDonald, 1983). More rapid development time as a consequence of enhanced metabolic activity could then be due to increased enzyme activities and/or the alteration of the cytosol NAD/NADH equilibrium and its subsequent re-attainment.

The survival results may be due to the fact that since temperature affects all metabolic processes, 
acceleration of development rate may be adaptive at low temperatures but detrimental at higher temperatures under nutritional stress. In the latter case metabolic and physiological processes may be at an upper limit and, if this is exceeded, survival may be affected (Kohen et al., 1970; Hochachka and Somero, 1984). Kohen et al. (1970) studied ascite cell cultures and found that whilst glycolytic flux could be increased by raising the temperature from $23^{\circ} \mathrm{C}$ to $37^{\circ} \mathrm{C}$, there was a maximum level of glycolytic flux which could not be increased by higher temperature. The magnitude of this effect was related to the preheating level of glycolytic activity in the extramitochondrial space. Further, maximum increase in glycolytic flux at the higher temperatures occurs in conditions where, at room temperature, NADH reoxidation (probably by $\mathrm{LDH}$ ) lags behind $\mathrm{NAD}^{+}$reduction by glyceraldehyde-phosphate dehydrogenase, either when glycolytic $\mathrm{NAD}^{+}$is being reduced too fast (in the presence of phosphate) or when NADH is being reoxidised too slowly (in the presence of lactate). This lag in NADH reoxidation was usually associated with a lowering of glycolytic flux at room temperature which thus could benefit from temperature increase (Kohen et al., 1970). Thus, an effect analogous to temperature increase could arise after NAD supplementation-an alteration in the NAD/NADH equilibrium and increased metabolic activity from a temperature-specific base level leading to decreased development time. This effect would be expected to diminish as temperature increased and this was observed in the experiments presented.

Thirdly, supplemented NAD could have interconverted the constituent isozymes of a variety of allozymes (Dunn et al., 1969; Wilkinson, 1970; Page, 1976; Lehninger, 1982). The decreased larval development time observed in the presence of NAD could thus be due to relatively more efficient isozyme profiles being available for metabolic activity in the stressful conditions. Data for Adh are relevant here since NAD together with a carbonyl compound can interconvert ADH isozymes with subsequent changes in the functional abilities of the allozymes (Jacobson, 1968; Ursprung and Carlin, 1968; Dunn et al., 1969; Jacobson et al., 1970, 1972; Knopp and Jacobson, 1972; Schwartz et al., 1975; Schwartz and Sofer, 1976; van Delden and Kamping, 1980; Winberg et al., 1982; McKechnie and Geer, 1984). Finally, it is suggested that supplemented NAD directly enhances electron flow into the electron transport chain and therefore directly affects energy availability during development (fig. 1). The hypothesis proposed is that enhanced energy availability at the cellular level can be regarded as being equivalent to enhanced gene expression, such that developmental processes are accelerated. The fact that development was accelerated in the presence of NAD seems to support this hypothesis. Since the above explanations are related, any conclusions regarding the physiological and metabolic effects of temperature, nutrient stress and NAD upon larval development must await further experiment.

Turning to the allozyme polymorphisms, the results show no significant differences between genotypes for both Adh and Gpdh. There was also no evidence for a fitness interaction between both loci as found in the presence of ethanol by Cavener and Clegg $(1978,1981)$. This lack of significant genotypic effects contrasts with many other laboratory studies for these loci (Berger, 1971; McKechnie et al., 1981; van Delden, 1982; Cavener, 1983) and could be due to statistical limitations associated with the experiments presented here. Data sets were relatively small and hence, detection of small selection coefficients which are to be expected for allozyme loci was restricted (Lewontin, 1974). There is also the limited power of the survival data in detecting genotypic effects since genotypic fitness differences were primarily estimated indirectly by comparisons between experimental and control survival levels rather than directly by comparisons between surviving and dead flies. The latter experiments generally require manipulation of strains in the laboratory which was considered important to avoid since significant results for Adh are frequently associated with laboratory strains and not with strains recently derived from the field (Oakeshott, Gibson and Wilson, 1984; Kohane and Parsons, 1986).

The non-significant results also possibly indicate a requirement for supplementation of the substrates of the enzymes studied-ethanol for ADH and dihydroxyacetone phosphate for GPDH. For example, dietary ethanol and sucrose can modulate ADH and GPDH in D. melanogaster larvae (McKechnie and Geer, 1984; Geer et al., 1983). Further, the chosen environmental conditions may not have been sufficiently stressful for field larvae (Kohane and Parsons, 1986), although genotypic differences have been detected under similar conditions for laboratory adapted larvae (De Jong and Scharloo, 1976; McKechnie et al., 1981; McKechnie and Morgan, 1982). Therefore, together with the proposed temperature $\times$ NAD interaction, exposures to temperatures less than $15^{\circ} \mathrm{C}$ and greater than $29^{\circ} \mathrm{C}$, increased nutritional 
stress and substrate supplementation at extreme and optimal levels may be required to demonstrate selection upon single loci for field larvae.

This paper has been concerned with assessment of the effects of environmental stress and altered energy availability upon larval fitness in $D$. melanogaster. Results indicated significant effects at the phenotypic level but not at the genotypic level for allozyme loci. These results therefore support Kohane and Parsons (1986) and suggest that a phenotypic approach studying environmental stresses and altered energy availability may be useful in the assessment of fitness variation in $D$. melanogaster populations. For example, study of isofemale strains differing in survivorship and development time under conditions of stress and qualitative and quantitative variation in energy availability is considered relevant. Further, extrapolation of the phenotypic approach to the genetic level (Thompson and Thoday, 1979; Parsons, 1980) may more precisely resolve the roles of allozyme loci such as Adh and Gpdh in stress tolerance and energy metabolism than is the situation as discussed above and as indicated in the literature. Finally, the approach outlined here may enable direct assessment of how variation in energy flow through organisms is translated into genotypic fitness differences, leading to an improved understanding of the bioenergetic constraints imposed upon evolutionary change (Watt, 1986).

Acknowledgements I am grateful to Professor Peter Parsons and Dr John Oakeshott for helpful discussions and criticism of the manuscript. I also acknowledge the financial assistance of a La Trobe University Scholarship.

\section{REFERENCES}

AYAlA, F. J., POWELL, J. R. AND TRACEY, M. L. 1972. Enzyme variability in the Drosophila willistoni group. IV. Genic variation in natural populations of Drosophila willistoni. Genetics, 70, 113-139.

BAKKER, K. 1961. An analysis of factors which determine success in competition for food among larvae of Drosophila melanogaster. Arch. Neerl. Zool., 14, 200-281.

BERGER, E. 1971. A temporal survey of allelic variation in natural and laboratory populations of Drosophila melanogaster. Genetics, 67, 121-136.

BRANDEN, C. AND EKLUND, H. 1980. Structure and function of liver alcohol dehydrogenase, lactate dehydrogenase, and glyceraldehyde-3-phosphate dehydrogenase. Jeffrey J. (ed.). In Dehydrogenases Requiring Nicotinamide Coenzymes. Birkhausen-Verlag, Basel, pp. 40-84.

CAVENER, D. R. 1983. The response of enzyme polymorphism to development rate selection in Drosophila melanogaster. Genetics, 105, 105-113.
CAVENER, D. R. AND CLEGG, M. T. 1978. Dynamics of correlated genetic systems. IV. Multilocus effects of ethanol stress environments. Genetics, 90, 629-644.

CAVENER, D. R. AND CLEGG, M. T. 1981. Multigenic adaptation to ethanol in Drosophila melanogaster. Evolution, 35, 1-10.

CHAYKin, S. 1967. Nicotinamide Coenzymes. Ann. Rev. Biochem., 36, 149-170.

CLARKE, B. 1975. The contribution of ecological genetics to evolutionary theory: Detecting the direct effects of natural selection on particular polymorphic loci. Genetics, 79, 101 113.

CONWAY, A. AND KOSHLAND, D. E. JR. 1968. Negative cooperativity in enzyme action. The binding of Diphosphopyridine nucleotide to glyceraldehyde 3-phosphate dehydrogenase. Biochem., 7, 4011-4022.

DE JONG, G. AND SCHARLOO, W. 1976. Environmental determination of selective significance or neutrality of amylase variants in Drosophila melanogaster. Genetics, 84, 77-94.

DUNN, G. R., WILSON, T. G. AND JACOBSON, K. B. 1969. Agedependent changes in alcohol dehydrogenase in Drosophila. J. Exp. Zool, 171, 185-190.

FIEGELSON, P., WILLIAMS, J. N. JR. AND ELVEHJEM, C. A. 1951. Inhibition of diphosphopyridine nucleotide-requiring enzymes by nicotinamide. J. Biol. Chem., 189, 361-369.

GEER, B. W., McKECHNIE, S. W. AND LANGEVIN, M. 1983. Regulation of sn-glycerol-3-phosphate dehydrogenase in Drosophila melanogaster larvae by dietary ethanol and sucrose. J. Nutrition, 113, 1632-1642.

HOCHACHKA, P. W. AND SOMERO, G. N. 1984. Biochemical Adaptation. Princeton University Press, Princeton, New Jersey.

JACOBSON, K. B. 1968. Alcohol dehydrogenases of Drosophila. Interconversion of isoenzymes. Science, 159, 324-325.

JACOBSON, B. K., MURPHY, J. B. AND HARTMAN, F. C. 1970 Isoenzymes of Drosophila alcohol dehydrogenase. I. Isolation and interconversion of different forms. $J$. Biol. Chem., 245, 1075-1083.

JACOBSON, B. K., MURPHY, J. B., KNOPP, J. A. AND ORTIZ, J. R. 1972. Multiple forms of Drosophila alcohol dehydrogenase. III. Conversion of one form to another by nicotinamide adenine dinucleotide or acetone. Archs. Biochem. Biophys., 149, 22-35.

JEFFrEY, J. 1980. Dehydrogenases Requiring Nicotinamide Coenzymes. Birkhausen-Verlag, Basel.

KNOPP, J. A. AND JACOBSON, B. K. 1972. Multiple forms of Drosophila alcohol dehydrogenase. IV. Protein fluorescence studies. Arch. Biochem. Biophys., 149, 36-41.

KOHANE, M. J. AND PARSONS, P. A. 1986. Environment-dependent fitness differences in Drosophila melanogaster: temperature, domestication and the alcohol dehydrogenase locus. Heredity, 57, 289-304.

KOHEN, E., KOHEN, C. AND THORELl, B. 1970. Microfluorimetric study of intracellular enzyme kinetics in single cells. Whelan, W. J. and Shultz, J. (eds.). In Homologies in Enzyme and Metabolic Pathways. Metabolic Alterations in Cancer. North-Holland, Amsterdam, pp. 481-515.

LEHNINGER, A. L. 1971. Bioenergetics; The Molecular Basis of Biological Energy Transformations. W. A. Benjamin, California.

LeHNINGer, A. L. 1982. Principles of Biochemistry. Worth, New York.

LEWONTIN, R. C. 1974. The Genetic Basis of Evolutionary Change. Columbia University Press, New York.

McELFRESH, K. C. AND McDONALD, J. F. 1983. The effect of alcohol stress on nicotinamide adenine dinucleotide $\left(\mathrm{NAD}^{+}\right)$levels in Drosophila. Biochem. Genet., 21, 365-374. 
McKeCHNIE, S. W. AND GEER, B. W. 1984. Regulation of alcohol dehydrogenase in Drosophila melanogaster by dietary alcohol and carbohydrate. Insect Biochem., 14, 231-242.

McKeCHNIE, S. W., KOHANE, M. AND PHILliPS, S. C. 1981. A search for interacting polymorphic enzyme loci in Drosophila melanogaster, Gibson, J. B. and Oakeshott, J. G. (eds.). In Genetic Studies of Drosophila Populations, Australian National University Press, Canberra, Australia, pp. $121-138$.

McKeCHNIE, S. W. AND MORGAN, P. 1982. Alcohol dehydrogenase polymorphism of Drosophila melanogaster: Aspects of alcohol and temperature variation in the larval environment. Aust. J. Biol. Sci., 35, 85-93.

OAKESHOTT, J. G., GIBSON, J. B. AND WILSON, S. R. 1984. Selective effects of the genetic background and ethanol on the alcohol dehydrogenase polymorphism in Drosophila melanogaster. Heredity, 53, 51-67.

PAGE, D. 1976. Principles of Biological Chemistry. Willard Grant Press.

PARSONS, P. A. 1980. Isofemale strains and evolutionary strategies in natural populations. Evol. Biol., 13, 175-217.

SCHWARTZ, M., GERACE, L., O'DONNELL, J. AND SOFER, W. 1975. Drosophila alcohol dehydrogenase: Origin of the multiple forms. Markert, C. L. (ed.). In Isozymes I. Academic Press, New York, pp. 725-751.

SCHWARTZ, M. AND SOFER, W. 1976. Diet-induced alterations in distribution of multiple forms of alcohol dehydrogenase in Drosophila. Nature, 263, 129-131.

THOMPSON, J. N. JR. AND THODAY, J. M. 1979. Quantitative Genetic Variation. Academic Press, New York.
URSPRUNG, H. AND CARLIN, L. 1968. Drosophila alcohol dehydrogenase: in vitro changes of isozyme patterns. Ann. N.Y. Acad. of Sci., 151, 456-475.

VAN DELDEN, w. 1982. The alcohol dehydrogenase polymorphism in Drosophila melanogaster. Evol. Biol., 15, 187222.

VAN DELDEN, W. AND KAMPING, A. 1980. The alcohol dehydrogenase polymorphism of Drosophila melanogaster. IV. Survival at high temperature, Genetica, 51, 179-185.

VEECH, R. L. 1974. The effects of ethanol on the free nucleotide systems and related metabolites in liver and brain. Thurman, R. G., Yonetani, T., Williamson, J. R. and Chance, B. (eds.). In Alcohol and Aldehyde Metabolizing Systems. Academic Press, New York, pp. 383-394.

VEECH, R. L., GUYNN, R. AND VELOSO, D. 1972. The timecourse of the effects of ethanol on the redox and phosphorylation states of rat liver. Biochem. J., 127, 387397.

WATT, W. B. 1985. Bioenergetics and evolutionary geneticsopportunities for new synthesis. Am. Nat., 125, 118-143.

WATT, W. B. 1986. Power and efficiency as indexes of fitness in metabolic organisation. Am. Nat, 127, 629-653.

WILKINSON, J. H. 1970. Isoenzymes. Chapman and Hall, London.

WINBERG, J., THATCHER, D. R. AND McKINLEY-McKEE, J. S. 1982. Drosophila melanogaster alcohol dehydrogenase: an electrophoretic study of the $A d h^{S}, A d h^{F}$ and $A d h^{C F}$ alleleoenzymes. Biochem. Genet., 21, 63-80. 